Leonardo Baldaçara

Centro de Atenção Integrada à Saúde Mental (CAISM), Santa Casa de São Paulo, São Paulo (SP), Brasil Fundação da Faculdade de Medicina do ABC, São Bernardo do Campo (SP), Brasil Laboratório Interdisciplinar de Neurociências Clínicas (LINC), Universidade Federal de São Paulo (UNIFESP), São Paulo (SP), Brasil

Karen Gennaro, Ricardo Uchida Centro de Atenção Integrada à Saúde Mental (CAISM), Santa Casa de São Paulo, São Paulo (SP), Brasil

Marsal Sanches

Centro de Atenção Integrada à Saúde Mental (CAISM), Santa Casa de São Paulo, São Paulo (SP), Brasil Faculdade de Ciências Médicas, Santa Casa de São Paulo, São Paulo (SP), Brasil

Financiamento: Inexistente

Conflito de interesses: Inexistente

Referências

1. Vieweg WV, Julius DA, Fernandez A, Beatty-Brooks M, Hettema JM, Pandurangi AK. Posttraumatic stress disorder: clinical features, pathophysiology and treatment. Am J Med. 2006;119(5):383-90.

2. Hamner M, Hunt N, Gee J, Garrell R, Monroe R. PTSD and automatic implatable cardioverter defibrillators. Psychosomatics. 1999;40(1):82-5

3. Luyster FS, Hughes JW, Waechter D, Josephson R. Resource loss predicts depression and anxiety among patients treated with an implantable cardioverter defibrillator. Psychosom Med. 2006;68(5):794-800

4. Neel M. Posttraumatic stress symptomatology in patients with automatic implantable cardioverter defibrillators: nature and intervention. Int J Emerg Ment Health. 2000;2(4):259-63.

5. Baumert J, Schmitt C, Ladwig KH. Psychophysiologic and affective parameters associated with pain intensity of cardiac cardioverter defibrillator shock discharges. Psychosom Med. 2006;68(4):591-7.

\section{Increased surgical morbidity of psychiatric patients submitted to appendectomy}

\author{
Morbidade cirúrgica aumentada de \\ pacientes psiquiátricos submetidos à \\ apendectomia
}

\section{Dear Editor,}

The general medical care offered to psychiatric patients tends to be worse than the one offered to the general population. It includes inappropriate management of highly prevalent diseases such as diabetes mellitus and systemic hypertension as well as a significant delay in the diagnosis of emergent clinical and surgical conditions leading to increased morbidity and mortality. ${ }^{1-2}$

In this preliminary report, we aim at presenting our evaluation of the hypothesis that patients with major psychiatric disorders submitted to appendectomy had delayed diagnosis and/or worse outcome when compared to control subjects. We searched for all records of patients over age 18 who underwent a surgical procedure (appendectomy) in a general hospital in the period from May, 2005 to August, 2006, all of them with real appendicitis evidenced by anatomopathologic exam carried out after the surgery. Appendectomy was selected due to the high incidence of appendicitis in the general population. ${ }^{3}$ We performed a chart review and the following data were evaluated: 1 ) the presence of a major psychiatric diagnosis according to DSM-IV criteria; 2) time elapsed from the onset of clinical symptoms to the surgical procedure (in days); 3) length of hospital stay (in days); and 4) number of postoperative complications. Coincidently only female psychiatric patients were identified $(n=10)$ based on retrospective psychiatric diagnosis (medical record and family information). Three patients had schizophrenia, four patients had recurrent depressive disorder, and three patients had bipolar disorder. The control group was comprised of female patients without current psychiatric disorders and/or receiving psychiatric treatment, who underwent the same surgical procedure at the same period $(n=81)$. A non-parametric test (Mann-Whitney) was used to compare the values between the groups. The results are shown in Table 1.

Table 1 - Surgical features of psychiatry and non-psychiatric patients submitted to appendectomy

\begin{tabular}{|c|c|c|c|}
\hline & Non-psychiatric $(n=81)$ & Psychiatric $(n=10)$ & $P$ value \\
\hline Age (years) & & & n.s. \\
\hline Mean (SD) & $27.02(4.23)$ & $25.50(2.79)$ & \\
\hline Median [range] & $26[19-35]$ & $25[20-30]$ & \\
\hline Interval between onset of symptoms and surgical procedure (days) & & & $<0.00$ \\
\hline Mean (SD) & $2.38(0.87)$ & $4.10(1.37)$ & ' \\
\hline Median [range] & $2[1-4]$ & $4[2-6]$ & \\
\hline Length of hospital stay (days) & & & n.s. \\
\hline Mean (SD) & $4.18(1.50)$ & $5.40(2.17)$ & \\
\hline Median [range] & $4[2-9]$ & $5[3-11]$ & \\
\hline Number of postoperative complications & & & 0.02 \\
\hline Mean (SD) & $1.02(1.11)$ & $1.80(0.91)$ & \\
\hline Median [range] & $1[0-3]$ & $2[0-3]$ & \\
\hline
\end{tabular}


Our results show that psychiatric patients had a longer interval between the onset of their symptoms and the surgical procedure. This may suggest that the patients postponed the search for medical care. An alternative explanation would be that their clinical symptoms could be erroneously attributed to their psychiatric disorder. A delayed diagnosis could be associated with more postoperative complications. ${ }^{2-3}$ In line with this, psychiatric patients had more complications than controls, although the length of hospital stay was the same for both groups. Other reasons for the increased morbidity in psychiatric patients in the postoperative period include: metabolic disorders related to the underlying disease or secondary to the use of psychiatric medications that have metabolic effects such as hyperglycemia, weight gain, and insulin resistance; inappropriate management of the psychiatric medication during the pre-, peri- and postoperative period, and the poor relationship among the members of the medical team (surgeons and psychiatrics).2,4

An interesting point that should be mentioned is the noninclusion of psychiatric patients in most studies that evaluate surgical indexes and features related to the morbidity and mortality of surgical procedures. ${ }^{5}$

Despite the evident limitations of our study (small sample, information obtained retrospectively and lack of laboratory or other clinical data possibly related to the outcome), the present results highlight the neglect of general medical problems in psychiatric patients.

Felipe Filardi da Rocha, Flávia Mello Soares, Humberto Correa

Department of Psychiatry, School of Medicine, Universidade Federal de Minas Gerais (UFMG), Belo Horizonte (MG), Brazil

Renata Figueiredo Rocha Service of Surgery, Santa Casa de Misericórdia Hospital, Belo Horizonte (MG), Brazil

Antônio Lúcio Teixeira Department of Internal Medicine, School of Medicine, Universidade Federal de Minas Gerais (UFMG), Belo Horizonte (MG), Brazil

Financing: None

Conflict of interests: None

References

1. Schneiderman G. Surgery and psychiatric practice. Can J Psychiatry. 1998;43(7):750.

2. Tsuang MT, Woolson RF. Mortality in patients with schizophrenia, mania, depression and surgical conditions. A comparison with general population mortality. Br J Psychiatry. 1977;130:162-6.

3. Cooke BK, Magas LT, Virgo KS, Feinberg B, Adityanjee A, Johnson FE. Appendectomy for appendicitis in patients with schizophrenia. Am J Surg. 2007;193(1):41-8.

4. Rocha FF, Bezerra BPS. Síndrome metabólica e transtornos psiquiátricos: uma associação que não pode ser esquecida. Arq Bras Endocrinol Metab. 2006;50(6):1138-9.

5. Abreu RA, Speranzini MB, Fernandes LC, Matos D. Feasibility analysis of loop colostomy closure in patients under local anesthesia1. Acta Cir Bras. 2006;21(5):275-8.

\section{More for the same?}

\author{
Mais pelo mesmo?
}

Dear Editor,

Andreoli et al. reported a significant decrease in the share for Mental Health (MH) in the Brazilian Public Health (SUS) budget. ${ }^{1}$ They refer to DATASUS as "limited", "unreliable", and unsuitable "for scientific purposes", as it fails to provide accurate information, for instance, on the number of psychiatric beds in general hospitals. Similar complaints were made in a recent audit performed by TCU, our High Court for Finances (www.contas.tcu.gov.br; Process 011.307/2004-9). The critical question is whether more investments should be made in the same model, as proposed by both publications.

Figure 1 shows 2,392 beds in 367 General Hospitals. However, 412 beds are in 224 hospitals with 4 or less beds. In the 90's, there were 2,156 beds in 139 General Hospitals. ${ }^{2}$ Clearly, Psychiatric Units in General Hospitals were never a priority.

Further information may help understand the budget issue:

1) Legislators and Government were told that community care was cheaper [e.g., "... a de-centralized model, with alternative, more efficient, more humane ... and less expensive..." (Sen. L. Alcântara report, 11/1995); ${ }^{3}$ or "... resources... channeled to other forms of care, less expensive and certainly revolutionary in their objective of socially including the psychiatric patient" (Sen. S. Rocha, 12/1998)]. ${ }^{3}$

2) Governments often divert money away from $\mathrm{MH}$ [e.g., "In many countries which adopted the deinstitutionalization policy, the community care is not reliable and is lacking in both financial and trained human resources ... many Ministries of Finance did not channel the budget of closed mental hospitals into other forms of mental health care services". ${ }^{4}$

3) According to the TCU audit, our MH system suffers from "severe managerial deficiency".

WHO praises the current CAPS-centric model (1,011 CAPS; only 37 open 24hs; 22,000 jobs; few psychiatrists; R\$ 168 million/year; never evaluated). However, it derives from "Il progetto dell'Instituto Mario Negri", the institution which sponsored the "Caracas Conference". ${ }^{5}$ In 2006, Brazil had 39,567 psychiatric beds (reimbursed at US\$17/day) or 2.2 beds/10,000 inhabitants ("Saúde Mental em dados 3", CORSAM, December, 2006). From the 120,000 beds supposedly available in the late 70 's, ${ }^{3}$ the reduction of 80,000 beds corresponds to $67 \%$ (actually, to $78.6 \%$, given the 65 million population growth), not just the recent $41 \%$ change. Moreover, 20,000 beds are currently used for long-term patients; modern medications are not reimbursed for bipolar disorders; and ECT is not recognized as treatment. Clearly, this system does not provide the most efficient care.

Patients are in the streets, jails and prisons, emergency services, or locked at home. TCU recommends modifications in the training of psychiatrists to conform to the "psychiatric reform". Conversely, severe criticism comes, among others, from the President of the Brazilian Psychiatric Association and from the President of the 2006 Brazilian Congress of Psychiatry (see Psiquiatria Hoje, December 2006). After two decades of "dehospitalization", we know that what needs reform is this failed $\mathrm{MH}$ model.

Valentim Gentil Department of Psychiatry, Universidade de São Paulo (USP) Medical School, São Paulo (SP), Brazil 